\title{
EL ALUMNO GERBER (VIENA, 1929): ALGO MÁS QUE UNA NOVELA ESCOLAR
}

EL ALUMNO GERBER, por FRIEDRICH TORBERG. Barcelona: Acantilado, 2016, 317 páginas. ISBN: 978-84-16011-91-9. Traducción del alemán de Marina Bornas Montaña.

LA TÍA JOLESCH, O LA DECADENCIA DE OCCIDENTE EN ANÉCDOTAS, por FRIEDRICH TORBERG. Barcelona: Alba, 2014, 390 páginas. ISBN: 978-84-8428-996-8.

LA CIUDAD SIN JUDÍOS, por Hugo Bettauer. Cáceres: Editorial Periférica, 2015, 173 páginas. ISBN: 978-84-16291-23-6. Posfacio de Murray G. Hall.

No cabe la menor duda de que a raíz del centenario de la Gran Guerra (1914-1918) se ha puesto sobre la mesa la desintegración del Imperio austrohúngaro, cuestión que ha concitado la atención de historiadores y politólogos. Mientras el Imperio alemán mantuvo su integridad política -aunque perdió importantes territorios en el este y en el oeste-, el austrohúngaro fue liquidado a través de un proceso que François Fetjö ha achacado a la voluntad republicanizadora de Francia. Más aún, se trataba de un intento de limitar la influencia de la Iglesia católica, siempre protegida por la dinastía de los Habsburgo. ${ }^{1}$ De este modo, el Imperio austrohúngaro dio lugar a la aparición de varias repúblicas, entre las que destaca la austríaca que, con la capitalidad vienesa, se convirtió en un interesante laboratorio pedagógico que la situó a la cabeza de la vanguardia educativa. Sin embargo, las reformas educativas se centraron en la educación infantil y primaria, en una Viena que después de la guerra vivía acuciada por los problemas sociales con una infancia depauperada al borde de la miseria. Curiosamente, en el viaje pedagógico realizado por Concepción Sainz-Amor a Viena, entre los meses de noviembre de 1932 y enero de 1933, gracias a una pensión de la Junta para Ampliación de

\footnotetext{
${ }^{1}$ François Fejtö, Réquiem por un imperio difunto. Historia de la destrucción de Austria-Hungría (Madrid, Encuentro, 2016).
} 
Estudios, no se abordó la educación secundaria que, a fin de cuentas, es la que retrata Torberg en la novela sobre el alumno Gerber. ${ }^{2}$

Cuando Concepción Sainz-Amor dictó en 1933 su conferencia en el Seminario de Pedagogía de la Universidad de Barcelona, que dirigía Joaquín Xirau, Hitler ya había accedido al poder en los últimos días del mes de enero de aquel año. Poco después se establecía en Austria, en 1934, un régimen autoritario - el austrofascismo- que abría la puerta a la germanización y al totalitarismo. Finalmente, se produjo la anexión (Anschluss) de 1938, consumada durante la noche del 11 al 12 de marzo, cuando los vagones de los fugitivos del nazismo - escribe Torberg- no pudieron abandonar Austria. ${ }^{3}$

Lo que de verdad era austríaco en la Vieja Austria, lo que constituía las cualidades auténticas, las cualidades incomparables e insustituibles de esta curiosa construcción estatal, lo que en otro tiempo mantuvo unido al círculo cultural negro y amarillo, todo esto, en fin, no desapareció definitivamente hasta $1938 .{ }^{4}$

También Sándor Marai coincide en este punto, al señalar que el Anschluss supuso la quiebra definitiva del Imperio austrohúngaro, lo que implicó además la aplicación de medidas antisemitas después de una serie de años de propaganda en esta dirección. ${ }^{5}$ Está claro que Viena desempeñó un papel crucial en el tema de la cuestión judía, ya que el antisemitismo - término que apareció en 1879- propició la aparición del sionismo. En efecto, después del affaire Dreyfus, Theodor Herzl —padre del sionismo- abandonó su posición en pro de la asimilación centrando en Viena sus actividades a favor de una nueva tierra para el pueblo hebreo. Al fin de cuentas, la llegada de judíos del este de Europa —consecuencia de los pogromos rusos fomentados por las autoridades desde 1871 y que se acentuaron a partir de 1904- alentó los vientos y disposiciones antisemitas. «En Viena, la llegada de los judíos procedentes del ámbito rural exacerbó el antisemitismo de la población. Desde 1900 judíos y turcos

\footnotetext{
${ }^{2}$ Isabel Vilafranca y Conrad Vilanou, «Concepción Sainz-Amor: Viena, laboratorio de pedagogía», Historia de la Educación. Revista Universitaria, 20 (2001): 449-465.

${ }^{3}$ Friedrich Torberg, La tía Jolesch, o la decadencia de Occidente en anécdotas (Barcelona, Alba, 2014), 349.

${ }^{4}$ Torberg, La tía Jolesch, o la decadencia de Occidente en anécdotas, 344.

${ }^{5}$ Sándor Marai, Lo que no quise decir (Barcelona, Salamandra, 2016), 9.
} 
eran los únicos que vestían con su traje nacional por las calles de la ciudad». ${ }^{6}$ Como es sabido, la presencia judía en el Imperio no era una cosa ligada a una determinada zona geográfica sino que estaban diseminados por todo el extenso territorio.

A decir verdad, los judíos vieneses — que vivían mayoritariamente en el distrito de la Leopoldstadt- representaron un motor de innovación y cambio en la Europa de entre siglos, el período intersecular. ${ }^{7}$ No por azar, los judíos reformularon la idea de Bildung, fraguando una síntesis cultural judío-alemana, que se manifiesta en la modernidad vienesa de finales del XIX y comienzos del Xx, fruto — como señala Le Rider- de artistas, literatos, teóricos y científicos judíos. ${ }^{8}$ De alguna manera, los judíos — excluidos tradicionalmente de la cultura - participaron del «ideal goethiano y humboltiano de la cultura personal (Bildung) como forma de contribuir y participar en la cultura colectiva (Kultur)». ${ }^{9}$ Torberg deja constancia, por ejemplo, de que del club deportivo judío Hakoah, un referente para el futbol austríaco y para los judíos de todo el mundo, «salían maestros austríacos en casi todas las modalidades deportivas», en un momento en que la práctica deportiva y la iniciación sexual se incorporaron al concepto de la idea de formación (Bildung). ${ }^{10}$

Naturalmente, muchos han sido los autores - Joseph Roth, Stefan Zweig, Arthur Schnitzler, Massimo Cacciari, Allan Janik y Stephen Toulmin, etc. - que se han referido a la capital austríaca. A esta ingente bibliografía, hay que añadir el libro de Jacques Le Rider que, entre otros aspectos, revisa las grandes figuras de la modernidad vienesa: Freud, la fidelidad al judaísmo desde la racionalidad científica; un literato judío, austríaco y alemán como Arthur Schnitzler; la Joven Viena literaria y la identidad judía - Hugo von Hofmannsthal, Richard Beer-Hofmann, Felix Salten-; las paradojas de Karl Krauss, director de la revista Die Fackel (La Antorcha); Stefan Zweig, «buen europeo» y ciudadano del mundo; y, por último, Gustav Mahler y Arnold Schönberg, música e identidad judía.

\footnotetext{
${ }^{6}$ William M. Johnston, El genio austrohúngaro. Historial social e intelectual (1848-1938) (Oviedo, Krk ediciones, 2009), 112.

${ }^{7}$ Le Rider, Los judíos vieneses en la Belle Époque (Barcelona, Ediciones del Subsuelo, 2016), 382.

${ }^{8}$ Le Rider, Los judios vieneses en la Belle Époque, 21.

${ }^{9}$ Le Rider, Los judíos vieneses en la Belle Époque, 34.

${ }^{10}$ Torberg, La tía Jolesch, o la decadencia de Occidente en anécdotas, 63.
} 
Al cabo, Viena significa - a pesar de la desaparición del Imperio en 1918- el centro nuclear del genio austrohúngaro, según sintetizó William M. Johnston en un libro de más de 1000 páginas que se ha convertido en una referencia ineludible. Y aunque no todos fueron judíos - Johnston recuerda que Brentano y Mach eran católicos-, lo cierto es que «la clase media judía proporcionaba un foro inigualable para la discusión y divulgación de las nuevas ideas». ${ }^{11}$ En realidad, Friedrich Torberg (Viena, 1908-1979) también participaba de los intereses de esta clase media judía, instalada en Viena, ciudad proclive al cultivo de las artes y las letras.

Tampoco hay que pasar por alto que la vida vienesa pone al descubierto el fracaso de la asimilación judía, un proceso que siguió al de su emancipación, que en Austria solo se dio después de 1848 y, especialmente, a partir de $1867 .{ }^{12}$ Mientras tanto el estudio del hebreo - constata Johnston - favorecía la imaginación, de la misma manera que lo hacía la prohibición de realizar imágenes de Dios. «El manejo del lenguaje contribuyó a mitigar las humillaciones infligidas a los judíos por los gentiles»..$^{13}$ Esta fascinación por el lenguaje - además de políglotas, los judíos hablaban una especie de dialecto judío-vienés- se confirma en los casos de Wittgenstein y Freud, dos referentes vieneses, como también sucede con Karl Kraus y Hugo Bettauer. Los primeros en el campo del pensamiento, los segundos en el terreno de la literatura satírica. Además, estos últimos autores han sido recuperados recientemente; primero con una notable antología de Kraus y un excelente estudio monográfico, y ahora con la traducción de La ciudad sin judíos (1922), la obra más significativa de Hugo Bettauer. ${ }^{14}$

Ciertamente la palabra ocupa un lugar de privilegio en el cenáculo judío vienés que se canaliza a través de múltiples manifestaciones teatrales, periodísticas y humorísticas. La presencia judía competía, pues, con la alemana, de modo que la palabra — en manos de la minoría hebrea- se convierte en un arma del pensamiento y de la crítica. También hay que

\footnotetext{
${ }^{11}$ Johnston, El genio austrohúngaro. Historial social e intelectual (1848-1938), 103.

12 Johnston, El genio austrohúngaro. Historial social e intelectual (1848-1938), 111.

${ }^{13}$ Johnston, El genio austrohúngaro. Historial social e intelectual (1848-1938), 107.

${ }^{14}$ Karl Kraus, La Antorcha. Selección de artículos de Die Fackel (Barcelona, Acantilado, 2011); Sandra Santana, El laberinto de la palabra. Karl Kraus en la Viena de fin de siglo (Barcelona, Acantilado, 2011).
} 
tener presente la palabra hablada que formaba parte de las conversaciones que se mantenían en las redacciones de los periódicos en que Torberg trabajaba y en las tertulias de los cafés. Aunque se ha escrito mucho sobre los cafés vieneses, podemos traer a colación la teoría del Café Central (1926), de Alfred Polgar, hijo de judíos asimilados que ha sido considerado el «maestro de la miniatura»,

unas miniaturas que reflejan a la perfección los rasgos que se han apuntado como propios del lenguaje de los judíos vieneses al final del Imperio austrohúngaro (fruto en parte de la enseñanza del hebreo y una manera también de sublimar la humillación): la capacidad para la asociación, la duplicidad de significados y los juegos de palabras, el gusto por el retruécano, la ocurrencia, la paradoja. ${ }^{15}$

Al paso, podemos establecer un paralelismo entre las miniaturas de Polgar y las anécdotas de Torberg, ya que ambas responden a una tendencia minimalista. En fin, en aquel contexto en que el imperio daba sus últimos coletazos, antes de su desaparición total en 1938, la palabra poseía una gran fuerza, al articularse en anécdotas, tal como hace en La tía Jolesch, una estrategia —el recurso a la anécdota- inspirada en Franz Molnár. Al margen de lo gracioso, la anécdota implica la «condensación precisa de lo esencial en un espacio mínimo». ${ }^{16}$ En cualquier caso, Polgar - al desarrollar su teoría del Café Central, probablemente el más emblemático de Viena- no duda en señalar lo siguiente: "El centralista vive parasitariamente de la anécdota que circula en torno a él. Esto es lo más importante, lo esencial». ${ }^{17}$ En suma, anécdotas y miniaturas literarias sirven para dar cuenta y razón de un mundo que caminaba hacia el ocaso.

Por su parte, Hugo Bettauer — nacido en 1872- ironiza en La ciudad sin judíos (1922) sobre la vida vienesa sin la presencia judía. ${ }^{18}$ Bettauer

\footnotetext{
${ }^{15}$ La eternidad de un día. Clásicos del periodismo literario alemán (1823-1934) (Barcelona: Acantilado, 2016), 146. Prólogo, selección, notas y traducción de Francisco Uzcanga Meinecke.

${ }^{16}$ Torberg, La tía Jolesch, o la decadencia de Occidente en anécdotas, 270.

${ }^{17}$ La eternidad de un día. Clásicos del periodismo literario alemán (1823-1934), 154.

${ }^{18}$ Hugo Bettauer, La ciudad sin judíos (Cáceres, Editorial Periférica, 2015), 173. Posfacio de Murray G. Hall.
} 
murió trágicamente al ser objeto de un atentado por parte de un fanático que le disparó un tiro, el 10 de marzo de 1925, al ser acusado de quebrantar la moral desde la revista Er und Sie (Él y Ella), que dirigía desde 1924, un "semanario para la cultura vital y el erotismo» que fue denunciado por presunta pornografía. ${ }^{19}$

Nada es como antes después de la expulsión de los judíos, según se narra en esta obra que Murray G. Hall considera, en su posfacio, una "pequeña novela de futuro», una macabra historia de anticipación que los jerarcas nazis - Alfred Rosenberg especialmente- debieron tener en cuenta para prever los pasos a seguir y evitar la hecatombe económica que suponía la expulsión de los judíos de la comunidad austríaca. De hecho, Bettauer presenta una radiografía de las diferentes posiciones políticas en torno a la cuestión judía en aquella incipiente república austríaca. Los socialcristianos y los nacional-germánicos estaban en contra de los judíos, defendidos por la minoría socialdemócrata. Además, los personajes de esta novela de anticipación son identificables con quienes regían la política austríaca desde la cancillería o desde el consistorio vienés. Así Murray G. Hall no duda en apuntar al dirigente obrero socialcristiano Leopold Kunschak como el «padre espiritual» de la novela, desde el momento que alentó disposiciones contra los judíos. Por tanto, Bettauer partió de una realidad histórica, que colocaba a la minoría judía en una situación de vulnerabilidad y marginación y, a la larga, de exclusión y expulsión.

Por ello, el borrador de Kunschak puede considerarse moderado si lo comparamos con las pretensiones del Partido Obrero Nacionalsocialista de Hitler (1920). «A diferencia de Kunschak —escribe Murray G. Hall en el posfacio- estos últimos aún no hablan de campos de concentración. Kunschak, en un largo discurso pronunciado en la Asamblea Nacional Constituyente el 29 de abril de 1920, los contempla como una solución, aunque hay que subrayar que el concepto tenía entonces un significado completamente distinto al que tiene en la actualidad». ${ }^{20}$ Por su parte, a comienzos de la década de los años veinte, en Austria aparecían títulos - por lo general de autores cristianos- cargados de un profundo antisemitismo, con lo cual el caldo de cultivo crecía hasta llegar al Anschluss

\footnotetext{
${ }^{19}$ Bettauer, La ciudad sin judios, 171.

${ }^{20}$ Bettauer, La ciudad sin judíos, 163.
} 
de 1938, un sueño para los partidarios —austríacos y alemanes- del pangermanismo. Según recuerda Torberg, el 1 de mayo de 1933, los nazis obtuvieron por vez primera la autorización para desfilar por las calles vienesas, un mal augurio que culminó con la anexión de 1938.

El sueño de una Viena aria y cristiana se impone al de una Viena cosmopolita, democrática y tolerante que Stefan Zweig ejemplariza según plantea Jacques Le Rider en su libro. En cierto sentido, la sátira constituye la instancia que pone al descubierto la cara más perversa de la condición humana. Ante la imposibilidad de dar cuenta y razón de todos los entresijos de La ciudad sin judios, conviene precisar algunos puntos de su argumento. La aprobación por el Parlamento austríaco de una ley antijudía a fin de salvaguardar la identidad aria y cristiana del país con lo que se dictan normas de expulsión que son aceptadas por los sionistas "porque responde a nuestras metas». ${ }^{21}$ La paradoja surge bien pronto, cuando se comprueba que muchas familias cristianas tienen su sangre mezclada con la judaica.

Ahora bien, después de unas semanas de alegría en las calles de Viena, la expulsión de los judíos comportó — siempre según la novela- funestas consecuencias para la marcha económica de la ciudad. Los negocios pierden la clientela judía. Así, la alta costura, los restaurantes, los cafés, los joyeros, los tenderos, etc., se quedan sin clientes y entran en crisis. Los banqueros vieneses carecen de la pericia de los judíos que saben aconsejar e invertir en el extranjero. El precio de los alquileres - a pesar de que los judíos han dejado muchas viviendas libres - se incrementa, con el consiguiente perjuicio para la población vienesa. La corona se devalúa y la inflación crece sin cesar. Más de un nuevo rico, que se aprovechó de la expulsión de los judíos, entra en quiebra. En las calles se ven jóvenes de cruz gamada, hasta el punto que «casi todos los hombres y mujeres, niños y adolescentes llevaban la insignia, que proliferaba en banderas y emblemas». ${ }^{22}$ Si primero se acusó a los judíos vieneses de todos los males, ante el descalabro económico que se avecinaba se atacó al judaísmo internacional que contaba con la ayuda de la masonería, articulando una conjura judeomasónica que más tarde sería bien conocida en España.

\footnotetext{
${ }^{21}$ Bettauer, La ciudad sin judios, 23.

${ }^{22}$ Bettauer, La ciudad sin judios, 95.
} 
Si La ciudad sin judíos (1922) es una novela satírica, El alumno Gerber —aparecida el mes de marzo de 1930- incorpora notas trágicas sin desdeñar el estilo crítico respecto al sistema austríaco de educación secundaria. Curiosamente, Torberg no refleja en su novela escolar atisbo alguno de manifestaciones antisemitas en aquellos establecimientos pedagógicos que frecuentaban los austrojudíos vieneses que, además, aceptaban la participación de los alumnos hebreos en servicios religiosos juveniles «que siempre se celebraba el primer sábado del mes y en el que los escolares judíos, en la terminología oficial denominados sin miramientos "escolares de la fe mosaica", participaban al completo». ${ }^{23}$

De todos modos, este afán por participar no se debía a razones religiosas sino puramente coyunturales ya que «significaba una reducción de dos horas del tiempo de clase». Con todo, y por aquel entonces, el joven Torberg —que escribió El alumno Gerber con solo 22 años-confiaba todavía en la asimilación en un momento en que si, algunas familias judías abandonaban la observancia religiosa, otras se distinguían — como la parte húngara de la familia de Torberg - por combinar la religiosidad con la erudición. No será superfluo resaltar que antes de 1938 vivían en Viena unos 250.000 judíos, aunque otras fuentes dan un censo de 185.000, lo cual no deja de tener su importancia si consideramos que, según Torberg, la cifra mundial de la comunidad judía ascendía entonces a 15 millones de personas. Sea como fuere, lo cierto es que en la ciudad de Viena, después de 1945, únicamente quedaron unos 10.000 judíos. $^{24}$

Pues bien, después de leer El alumno de Gerber, nos damos cuenta de que el mundo de ayer pervivió en Viena después del Tratado de Versalles (1919). Una Viena que rompía aquella imagen ideal dibujada por Stefan Zweig pero que, por los avatares de la historia, se mantuvo durante años. ${ }^{25}$ Pero a pesar de la ingenuidad de Zweig, que presenta Viena como el emporio de la tolerancia y la concordia social, siempre vivificada por la creatividad de la comunidad hebrea, no es menos verdad que en su retrato del mundo de ayer dirigió duras críticas a la educación, después de su escolarización a lo largo de trece años, cinco en primaria y ocho en el bachillerato. Su descripción de la escuela del siglo XIX no tiene des-

\footnotetext{
${ }^{23}$ Torberg, La tía Jolesch, o la decadencia de Occidente en anécdotas, 46.

${ }^{24}$ Torberg, La tía Jolesch, o la decadencia de Occidente en anécdotas, 380.

${ }^{25}$ Stefan Zweig, El mundo de ayer. Memorias de un europeo (Barcelona, El Acantilado, 2001).
} 
perdicio, ya que pone en evidencia su papel de garante del imperio. Para fortalecer la seguridad de aquel mundo, la escuela - ya fuese primaria o secundaria - ejercía una función en que se desconfiaba - como el Dios Kupfer - de niños y jóvenes. Se trataba de una enseñanza apática e insulsa, de espaldas al mundo de la vida, que propugnaba un aprendizaje pasivo y memorístico encaminado a superar los exámenes.

En realidad, la situación reflejada por Zweig y Torberg es parecida, aunque entre ambos hubiesen cambiado las circunstancias, como mínimo políticamente al pasar Austria de imperio a república. Recordemos que Zweig nació en 1881 y que Torberg lo hizo en 1908. Pero a pesar de la diferencia de edad, sus recuerdos escolares son similares, por no decir idénticos, más todavía si tenemos en cuenta que en medio se produjo la Primera Guerra Mundial. Los profesores continuaban sentándose en la tarima para reafirmar aquella falsa seguridad del mundo de ayer, con lo cual se confirma la tesis de Torberg y otros autores en el sentido que el Imperio austrohúngaro perduró hasta 1938. Un mundo en que se desconfiaba del alumnado y la educación se convertía en instrumento de poder para mantener la autoridad, con lo que los alumnos únicamente tenían una posibilidad: escapar de la monotonía y aburrimiento escolar a través de los intereses artísticos, literarios y musicales. Los nuevos nombres -Rilke, Nietzsche y Strindberg - fueron los autores que leían aquellos jóvenes un tanto rebeldes frente a la tradición escolar que imponía creadores convencionales como Schiller. Al fin y al cabo, esta también fue la salida que siguió el alumno Gerber, lector apasionado de Lenau, poeta que fue su salvación cuando llegaron los exámenes finales.

Con este trasfondo no ha de extrañar que en Austria en 1934, después de que el canciller Dollfuss - que transformó el Partido Social Cristiano fundado por Karl Lueger, de tendencia antisemita, en el Frente Patriótico- disolviese el parlamento, a fin de instaurar un sistema político autoritario - el austrofascismo - bajo la forma de «Estado corporativo cristiano". Nos encontramos ante un régimen que, como señala Torberg, acabó con la democracia, supuso la entrada de los vientos del ultranacionalismo germano y el desarrollo del antisemitismo, de manera que la fecha de 1938 - año de la anexión- tiene un claro antecedente en el régimen instalado el $1934 .{ }^{26}$ En cualquier caso, hay que recordar que

\footnotetext{
${ }^{26}$ Torberg, La tía Jolesch, o la decadencia de Occidente en anécdotas, 259-260.
} 
ambos autores - Zweig y Torberg - pertenecían a familias austrojudías que, después de la emancipación, se habían asimilado a la vida pública imperial, que participaban de la misma y que, además, acudían a las escuelas sin mayores dificultades. Tal como señala Torberg, los judíos participaban de las dos tradiciones, de la religiosa talmúdica y de la cultura emancipada del café. ${ }^{27}$

Torberg, que nació en el seno de la comunidad judía de Viena, da cuenta y razón en el prólogo al libro del periodista austríaco Ernst Trost Lo que quedó del águila bicéfala. Tras la huella de la desaparecida monarquía danubina (1966), que ha sido incorporado a La tía Jolesch, o la decadencia de Occidente en anécdotas, de su historia familiar, ligada al apellido Kantor -que adquirió en el momento de la asimilación y que recuerda el oficio de la sinagoga-. Así reconoce que la asimilación fue absoluta, incluso en el ámbito militar, puesto que «los judíos fueron parte esencial de la monarquía». ${ }^{28}$ Además, se vivía en contacto con diversas realidades sociales, porque el imperio constituía un crisol cultural plurilingüe y diverso étnica y culturalmente. "Los Estados sucesores de la vieja Austria se reconocían con facilidad hasta 1938, algunos de ellos, como Checoslovaquia por su plurilingüismo, o Hungría por sus clases sociales, incluso con más facilidad que la nueva Austria. Hasta 1938». ${ }^{29}$

Se comprende así que Zweig en la conferencia que pronunció en París el 26 de abril de 1940, pocas semanas antes de la entrada de la Wehrmacht en la capital francesa, dibujase - frente al Berlín del nazismo- una Viena como «baluarte defensivo de una cultura superior» que nunca fue arrogante, donde imperó el espíritu cosmopolita y convivían militares y sacerdotes, pueblos y nacionalidades diversas - germanos, bohemios, eslovenos, húngaros y judíos- sin atisbarse ningún tipo de odio en la mentalidad vienesa, capital de la música y del teatro, esto es, de la cultura.

Cuando todavía iba al instituto, yo era sólo uno entre por lo menos dos docenas de alumnos que jamás se perdía ninguna función importante del Burgtheater o de la Ópera... Y ahora calculen estos veinticuatro de una sola clase multiplicados por cin-

\footnotetext{
${ }^{27}$ Torberg, La tía Jolesch, o la decadencia de Occidente en anécdotas, 213-214.

${ }^{28}$ Torberg, La tía Jolesch, o la decadencia de Occidente en anécdotas, 342.

${ }^{29}$ Torberg, La tía Jolesch, o la decadencia de Occidente en anécdotas, 345.
} 
cuenta escuelas, por una universidad, por la burguesía al completo, por la ciudad entera, y se harán una idea de la presión a la que estaba sometido todo lo que concernía a la música o al teatro. ${ }^{30}$

En fin, la Viena imperial representaba un emporio de cultura que, después de 1919, pasó a ser la capital de una pequeña república de cuatro millones de personas, frente a los cincuenta y cuatro millones de habitantes del viejo imperio. Justamente, a partir de este momento Berlín fue ganando protagonismo en la cultura germánica en detrimento de la Viena que había adquirido — desde la época imperial- la condición de ciudad civilizadora, con su refinamiento, tolerancia y cosmopolitismo. Eso es lo que aprendió Zweig de Viena, ciudad que en 1940 continuaba simbolizando a sus ojos un bastión ante la barbarie. Por ende, el papel reservado a Viena en el concierto de la cultura europea no era otro que el de «defender una cultura superior de las invasiones bárbaras». ${ }^{31} \mathrm{He}$ ahí, pues, la función reservada al arte, a la música y al teatro, que reclamaba el ejercicio de la libertad frente a la sinrazón del nazismo, con lo que se daba una nueva oportunidad a los planteamientos de Schiller en sus Cartas sobre la educación estética del hombre (1795) que enfatizaban, de acuerdo con la tercera crítica kantiana, el papel educador - y si se quiere, salvador- de la vía estética de cara a la formación del género humano.

Desde luego, esta imagen ideal de Viena —vista como capital de la cultura- no coincide estrictamente con la que se desprende de la novela escolar que Torberg escribió en 1929, cuando vivía a caballo entre Viena y Praga, al recordar el último año escolar —el octavo curso de bachillerato- pasado en el Realgymnasium XVI. Cuando se publicó al año siguiente, su autor contaba con solo veintidós años, de modo que la época escolar estaba bien presente en su universo mental que se vio alterado por el hecho de que tan solo en una semana —entre el 27 de enero y el 3 de febrero de 1929- «el autor tuvo noticia a través de la prensa escrita de diez casos de suicidio de escolares». ${ }^{32}$ Aquí radica la importancia de estas novelas escolares (Erziehungsroman) que ponen en entredicho visiones un tanto ideales como la que se desprende de la descripción vienesa de

\footnotetext{
${ }^{30}$ Stefan Zweig, «La Viena de ayer», en De viaje. Europa Central (Madrid: Ediciones Sequitur, 2015), 100.

${ }^{31}$ Zweig, «La Viena de ayer», 110.

${ }^{32}$ Friedrich Torberg, El alumno Gerber (Barcelona: Acantilado, 2016), 7.
} 
Zweig, una especie de república humanista de las letras y las artes, más propia del Renacimiento que de la modernidad científico-tecnológica. En última instancia, la novela escolar —emparentada con la Bildungsroman, pero que dio lugar a un género propio (Erziehungsroman) - servía de vehículo de denuncia de un sistema pedagógico obsoleto que coartaba la libertad del alumno, y que Thomas Bernhard lo consideró incluso antieducativo en su autobiografía titulada Die Ursache (El origen) publicada en $1975 .^{33}$

En el fondo, detrás de la opulencia de la cultura austríaca, con sus majestuosas salas de concierto y teatros, existía un mundo un tanto sórdido que mantenía el autoritarismo de épocas anteriores, hasta el punto que los gimnasios de educación secundaria se convertían en verdaderos rituales de paso que conducían hasta el bachillerato, un largo proceso no exento de coacciones y vejaciones que exigía superar con éxito el Abitur. Ahora bien, después de 1918, los cantos al emperador que era despertado por coros infantiles y la celebración del cumpleaños de Francisco José el 18 de agosto en toda la geografía imperial fueron suplantados por el aprendizaje de la Constitución Renovada que los profesores recitaban de carrerilla. ${ }^{34}$ Se puede añadir que la Constitución de 1920, que en el artículo primero declaraba que Austria es una república democrática, fue reformada en 1929 en el sentido de fortalecer al presidente y al ejecutivo en detrimento del poder legislativo, en sintonía con la consolidación del régimen fascista italiano.

La tiranía de algunos profesores recordaba la que habían ejercido los mandos militares durante la Primera Guerra Mundial, extremo que autores como Ernest Hemingway en A farewell to arms (1929), Emilio Lussu en Un anno sull'altipiano (1938) y Curzio Malaparte en Due anni di battibecco (1955), no dudaron en denunciar. En realidad, y según el relato de Torberg, Artur Kupfer —el profesor de matemáticas y geometría y tutor del curso, conocido como el «Dios Kupfer» debido a su infalibilidadhabía sido oficial durante la Gran Guerra, tal como proclamó el primer día de clase desde la tarima: «El capitán Kupfer (durante la guerra fui capitán) lo ve todo, lo nota todo, lo sabe todo». ${ }^{35}$ Según la descripción de

\footnotetext{
${ }^{33}$ Thomas Bernhard, El origen (Barcelona: Anagrama, 2001), 8.

34 Torberg, El alumno Gerber, 200.

35 Torberg, El alumno Gerber, 18.
} 
Torberg, Kupfer residía en casa de una baronesa viuda y en la pared de una de las habitaciones colgaban «tres fotografías en las que aparecía en uniforme, vestido de jinete montando a caballo y de tenista». ${ }^{36} \mathrm{~A}$ pesar de todo, fuera de la escuela Kupfer no ejercía el poder que poseía dentro del aula, de modo que era «un Dios de responsabilidad limitada».

Por lo demás, la infancia de Friedrich Torberg — que formaba parte de la minoría judía del imperio - transcurrió entre Viena y Praga. En $L a$ tía Jolesch, o la decadencia de Occidente en anécdotas nos ha dejado noticia de sus recuerdos de niñez y juventud. Digamos de paso que el apellido Torberg es una construcción a partir de la sílaba final del apellido paterno - Kantor - y el apellido de soltera de su madre —Berg-, con lo cual compuso el seudónimo Torberg, «que servía, según fuera necesario, para ocultar o demostrar mi identidad». ${ }^{37}$ Así pues, Torberg se escudó detrás del seudónimo para proteger una autoría que podía ser reconocida fácilmente de haber firmado con su nombre oficial, que finalmente fue substituido por el ficticio. Además, la anécdota — que podemos incluir en el panorama de la sátira vienesa, campo en el que sobresalió Karl Kraus con La Antorcha - constituye un valioso recurso literario, con una poderosa carga crítica que — tal como hemos señalado más arriba— responde a un formato literario minimalista. ${ }^{38}$

Aparte sabemos que Torberg en la vida real suspendió el examen de bachillerato (Abitur), tema central de su novela sobre el alumno Kurt Gerber que acaba suicidándose antes de conocer la calificación final de aprobado. A lo largo de la novela conocemos la distribución exacta de los compañeros en la clase, a la vez que renuncia por dos veces - ante la insistencia de sus progenitores - a cambiar de instituto ante la amenaza de fracaso por causa del Dios Kupfer. Mientras tanto, llegan al domicilio familiar cartas que notifican la deficiente marcha escolar de Kurt que suspende asignaturas en los exámenes parciales. Añádase a esto que Kupfer le impuso, por una falta, el castigo de cumplir cuatro horas de encierro en la celda. Si durante una temporada Gerber fue amigo de los malos alumnos, cuando cambió su actitud e interés no fue aceptado por los compañeros que obtenían mejores calificaciones. Su trayectoria era un

\footnotetext{
36 Torberg, El alumno Gerber, 33.

37 Torberg, La tía Jolesch, o la decadencia de Occidente en anécdotas, 219.

38 Torberg, La tía Jolesch, o la decadencia de Occidente en anécdotas, 270.
} 
tanto errática, mientras los padres se preocupaban continuamente por la evolución de sus estudios porque suspender el bachillerato suponía una auténtica tragedia en una sociedad meritocrática como la vienesa, donde se buscaba la seguridad de un puesto público, una vieja rémora del pasado imperial, de aquel mundo de ayer, recordado nostálgicamente por Zweig.

Al hilo de lo que decimos, se desprende que la educación secundaria en Viena mantenía las viejas costumbres imperiales: tarima, tratamiento de usted a los alumnos, disciplina férrea, rigidez escolar, control de la asistencia, pasividad en el aula, castigo disciplinario, exámenes difíciles, espíritu de competitividad entre los compañeros, diario de clase en que se anotaba cualquier nimiedad, avisos de expulsión, aunque se vislumbra alguna novedad como la presencia de chicas en el aula, mientras que los profesores hacían la vista gorda ante los cigarrillos. De hecho, el alumno Kurt Gerber vivió una gran pasión por Lisa Berwald, que abandonó los estudios después del séptimo curso y que empezó a trabajar, lo cual despertó aún más la dependencia hacia ella —una mujer joven y atractivadel protagonista de la novela —el otro yo de Torberg, esto es, Kurt Gerber- que con diecinueve años acabará sumido en el tedio y el desánimo. Lisa representa la mujer moderna que vive según los patrones que llegan de Norteamérica, que desde los 15 años tonteaba con unos y con otros. «Lisa abandonó el instituto, donde había estado más tiempo del esperado porque sus padres no sabían qué hacer con ella». ${ }^{39}$ En realidad, Lisa y su grupo de amigos - alegres y festivos - simbolizan las ansias de liberación de una juventud que había perdido los referentes de la tradición, el cumplimiento ciego del deber y que veía en la música, en el flirteo y la sexualidad unas magníficas oportunidades de diversión y evasión, periodo que coincide con la era del Jazz o la época del flirt. ${ }^{40}$ En fin, una juventud que vislumbraba en el bachillerato una farsa ridícula, y que reclamaba la vida libre ante una escuela opresora que servía para dilucidar quiénes eran los buenos alumnos que tenían derecho a progresar socialmente de acuerdo con un escalafón social que procedía de la etapa imperial.

Bien mirado, la relación que se establece entre el maestro (Kupfer) y el alumno (Gerber) recuerda la del suboficial respecto al soldado, una

\footnotetext{
39 Torberg, El alumno Gerber, 132.

${ }^{40}$ Rosa María Arquimbau, Cor lleuger i altres narracions de l'era del flirt (Barcelona, Comanegra, 2016).
} 
dialéctica de amo y esclavo, que solo puede acabar con la victoria del primero y la humillación del segundo. En realidad, Kupfer se ofreció voluntariamente a ser tutor del curso para arruinar y liquidar al joven Gerber, siempre arrogante, lo cual dificultaba que aprobase el curso, aunque sus padres - ante el temor del fracaso que se avecinaba- recurrieron como otras muchas familias a contratar un profesor particular para ayudar a su hijo, hasta el punto que algunas se arruinaban en el intento. La cosa llega al extremo de que la madre de Kurt se humilla ante el Dios Kupfer porque su esposo está gravemente enfermo y cualquier disgusto producido por las notas de su hijo podría quebrantar aún más la débil salud del padre. Pero Kupfer es inflexible y reclama el cumplimiento estricto del reglamento escolar que exige que el padre firme la notificación de la sanción aplicada al hijo. Poco después, el padre de Kurt discute con Kupfer que ha impuesto un castigo sin la convocatoria del claustro pertinente. Pero la lucha continúa y los temidos exámenes finales se acercan y el padre, que está pasando una temporada en un sanatorio, envía cartas al hijo exhortándole a que estudie. Kurt ha de aprobar, el suspenso significaría una catástrofe.

El capítulo dedicado a los exámenes finales sintetiza perfectamente el ambiente de aquellas situaciones que recuerdan a las antiguas reválidas. Kurt recibe un telegrama de sus padres el día del examen a primera hora, antes de desplazarse al instituto. El tribunal está integrado por profesores del centro y el inspector Marion. Kurt vacila en matemáticas ante la mirada de regocijo del Dios Kupfer. Con todo, al final aprueba el bachillerato por mayoría ya que, además de las matemáticas, el examen se completa con otras materias como el latín, el alemán y la geografía e historia. «No es necesario aprobar las cuatro asignaturas. Eso sería aprobar por unanimidad». ${ }^{41}$ Para estudiar Derecho o Filosofía basta con el aprobado por mayoría, pero Kurt duda porque, si en latín y alemán las cosas han ido bien, no ha sucedido lo mismo en geografía e historia.

Bástenos saber que, en caso de no alcanzar el grado de bachiller, las familias burguesas - deseosas de que sus hijos adquiriesen el prestigio académico que garantizase un buen empleo- veían en ello un auténtico fracaso, de manera que no extraña que algunos jóvenes decidiesen poner fin a su vida traumáticamente. Kurt, que finalmente fue aprobado, se

\footnotetext{
${ }^{41}$ Torberg, El alumno Gerber, 302.
} 
suicida antes de que conozca haber superado el Abitur, lo cual pone de manifiesto la contradicción del sistema escolar austríaco, la oposición entre escuela y vida, entre el bachillerato y el mundo de la vida, aquel Lebenswelt que reclamaba la fenomenología de Husserl, un campo abonado para las vivencias y las experiencias que sirven para encontrar el sentido de la vida, clave de bóveda del oficio de vivir.

En realidad, nos encontramos ante una novela escolar (Erziehungsroman) que refleja el ambiente pedagógico centroeuropeo durante los años de crisis del período de entreguerras (1919-1939). Fue entonces cuando una serie de jóvenes literatos se dedicaron a denunciar, a través de la narración de sus recuerdos, la rigidez del sistema escolar ya fuese prusiano o austríaco. En esta dirección, Herman Hesse dejó constancia en su novela autobiográfica Bajo la rueda (1905) de las peripecias escolares de Hans Giebenrath. Por su parte, Robert Musil en Las tribulaciones del estudiante Törless (1906) puso de relieve las contradicciones del Instituto W., una especie de internado de cadetes militares. De alguna manera todos coincidían en remarcar la rigidez de aquellos establecimientos pedagógicos - ya fuesen religiosos, civiles o militares-en que imperaban los principios del mundo de ayer, situación que hizo que muchos alumnos - y aquí el caso de Jünger es paradigmático — vieran el estallido de la Primera Guerra Mundial, y su consiguiente enrolamiento a filas, como una especie de liberación que, además, satisfacía sus ansias de aventura.

Pese a todo, no hay que perder de vista - como Erich Maria Remarque denuncia en Sin novedad en el frente (1929)_ que muchos maestros fueron los responsables de que los jóvenes se alistasen en 1914 en las oficinas de guerra, a la vez que se puede trazar un paralelismo entre el profesor, el pastor de almas y el suboficial. El primero con relación a los alumnos, el segundo con referencia a sus fieles y, por último, el cabo o sargento respecto a los reclutas. La figura de Kantorek -el profesor de gimnasia de Remarque- adquiere aquí toda su relevancia ya que, gracias a sus arengas, consiguió que toda la clase se presentase voluntariamente a la oficina de militarización. Remarque señala que estos pedagogos guardaban sus sentimientos en el bolsillo del chaleco haciéndolos públicos en cada momento, aunque al ser movilizados en su condición de reservistas no daban aquellas muestras de valentía y heroísmo que habían exigido a sus antiguos alumnos. 
De la novela de Torberg se deduce que la relación pedagógica - y por extensión, la relación humana- puede interpretarse como una especie de combate, de enfrentamiento, no solo entre el aula siempre artificial y la vida exterior del instituto, sino también entre el profesor y el alumno. La pizarra - y lo que comporta «salir a la pizarra»- se convierte en una especie de acto heroico, pero que cosecha muchos fracasos, que se asemeja al hecho de salir del parapeto de la trinchera, de la aparente seguridad del pupitre, para quedar a la vista de todo el mundo, siendo presa fácil del enemigo, de todos aquellos profesores que se asemejan al capitán-Dios, de un Dios limitado como Kupfer pero real, que ejerce su tiranía teocrática en el recinto del aula escolar. «Y la pizarra es una puerta de verdad. Una puerta cerrada. Detrás está la vida, quizá una madre contenta, o el amor, o un puesto en el servicio público, o quien sabe qué». ${ }^{42}$

En suma, El alumno Gerber se inscribe en el género literario de la novela escolar que ha dado diversas obras de referencia en la literatura germánica, ya fuese alemana o austríaca. Muchos años después del libro de Torberg llegó Reencuentro (1971), de Fred Uhlman, que retrata la vida del Karl Alexander Gymnasium de Stuttgart en los meses anteriores al ascenso del nazismo, en que también se deja constancia de la inconsistencia de un mundo que se tambaleaba, como aquella Viena de Zweig. "Ese era mi mundo, un mundo que yo creía absolutamente seguro e indudablemente eterno». ${ }^{43}$ Tampoco podemos dejar en el tintero Venganza tardía. Tres caminos a la escuela (1991) de Ernst Jünger, obra en que se evidencia el contraste entre la férrea disciplina escolar prusiana y la imaginación infantil en los años anteriores a la Primera Guerra Mundial.

Los maestros de la escuela preparatoria habían recibido una sólida formación en los seminarios. En ella se basaban su orgullo y su autoridad. Transmitir un saber sólido constituía su vocación y su empeño. Seguían el principio de que la repetición es la madre del estudio. Huelga decir que los alumnos inteligentes se aburrían en sus clases y que, sobre todo, les fastidiaba el aprendizaje memorístico y el recitado de la lección. ${ }^{44}$

\footnotetext{
42 Torberg, El alumno Gerber, 264.

${ }^{43}$ Fred Uhlman, Reencuentro (Barcelona: Tusquets, 1987), 62.

${ }^{44}$ Ernst Jünger, Venganza tardía. Tres caminos a la escuela (Barcelona: Tusquets, 2009), 24-25.
} 
Por ello, los alumnos dotados con imaginación -y Jünger fue uno de ellos- se encontraban incómodos en aquellos centros educativos, donde no siempre cosechaban buenas notas. Así Jünger —nacido en 1895- reconoce su dispersión ya que estaba más atento a dar rienda suelta a su imaginación que a las explicaciones de sus profesores. A fin de cuentas, la literatura juvenil - Verne, Salgari, Kipling, etc.— y la fantástica de viajes - Crusoe, Henry Stanley, etc. - estaba marginada del currículum escolar. ${ }^{45}$ En último término, algo similar sucedió con el alumno Gerber que en los exámenes finales obtuvo una buena calificación en la prueba de alemán en la cual se habían de desarrollar dos ejercicios, esto es, interpretar un poema y responder una pregunta de historia de la literatura relacionada con él. En el caso de Gerber, le correspondió comentar el poema Otoño (Herbst) de Nikolaus Lenau (1802-1850), poeta húngaro de padres alemanes que enloqueció y murió en Oberdöbling/Viena. Al leer la última estrofa del poema en voz alta «se dio cuenta de que la voz le temblaba ligeramente». ${ }^{46}$

Entonces fue cuando Gerber se transformó ante el tribunal, porque adoraba a Lenau y conocía su vida que explicó con tanta elocuencia que sus jueces académicos le invitaron a callar. A continuación se refirió, aunque sin captar la atención de todos los miembros del tribunal, a la lírica en Austria en los tiempos de la joven Alemania. En fin, el fracaso en matemáticas se compensó con el buen ejercicio de alemán, cuando pudo dar rienda suelta a sus sentimientos de manera entusiasta porque la vida de Lenau —el gran lírico austríaco, con sus viajes y amores, su locura y muerte- había encendido la pasión del joven Gerber ante un autor que adoraba. La lírica lo hubiera podido salvar, pero no fue así: la frialdad autoritaria del Dios Kupfer, con sus fórmulas matemáticas siempre abstractas, pudo más que la fuerza creativa del logos poético de Lenau. A pesar de ello, y aunque Gerber se suicida en la ficción novelesca, Torberg siguió una larga y fructífera carrera literaria, periodística y de ficción, en que descuella un título que recuerda el horror nazi, Mía es la venganza. ${ }^{47}$ No en balde, Torberg fue considerado uno de los diez eminentes escritores antinazi, título que ostenta junto a otros autores como Thomas Mann.

\footnotetext{
${ }^{45}$ Sobre este punto concreto, resulta clarividente la serie de notas y comentarios de Enrique Ocaña, traductor de Venganza tardía de Jünger, así como su posfacio, 109-116.

${ }^{46}$ Torberg, El alumno Gerber, 305.

${ }^{47}$ Friedrich Torberg, Mía es la venganza (Barcelona: Sajalín, 2011).
} 
Allí, en Mía es la venganza, el Dios Kupfer encuentra su remedo en la figura del jefe del grupo de la SS Hermann Wagenseil, comandante del campo de concentración de Heidenburg. Pero esta es otra historia que incorpora la dimensión pedagógica-salvífica del profetismo hebreo, con su carga optimista de la fe en Dios - Yahvé también educa- que, con el permiso del lector, dejamos para otra ocasión. ${ }^{48}$

\author{
Raquel Cercós i Raichs \\ Universitat de Barcelona \\ rcercos@ub.edu \\ Conrad Vilanou Torrano \\ Universitat de Barcelona \\ cvilanou@ub.edu
}

\footnotetext{
${ }^{48}$ La investigación que ha dado lugar a estos resultados ha sido impulsada por RecerCaixa.
} 